\title{
The cough reflex is upregulated by lisinopril microinjected into the caudal nucleus tractus solitarii of the rabbit
}

\author{
Elenia Cinelli, Fulvia Bongianni, Tito Pantaleo, Donatella Mutolo* \\ Dipartimento di Medicina Sperimentale e Clinica, Sezione Scienze Fisiologiche, Università degli Studi di Firenze, Viale G.B. Morgagni 63, 50134 Firenze, Italy
}

\section{A R T I C L E I N F O}

\section{Article history:}

Received 9 June 2015

Received in revised form 27 July 2015

Accepted 27 July 2015

Available online 30 July 2015

\section{Keywords:}

Lisinopril

Cough

Bradykinin

Substance P

Nucleus tractus solitarii

\begin{abstract}
A B S T R A C T
We have previously shown that cough potentiation induced by intravenous administration of the $\mathrm{AT}_{1}$ receptor antagonist losartan is lower than that induced by the ACE inhibitor lisinopril in anesthetized and awake rabbits. Since losartan and lisinopril cross the blood-brain barrier, their central action on the cough reflex can be hypothesized. Mechanical stimulation of the tracheobronchial tree and citric acid inhalation were used to induce cough reflex responses in pentobarbital sodium-anesthetized, spontaneously breathing rabbits. Bilateral microinjections (30-50 nl) of losartan (5 mM), lisinopril (1 mM), bradykinin (0.05 mM), HOE-140 (0.2 mM, a bradykinin $B_{2}$ receptor antagonist) and CP-99,994 (1 mM, an $\mathrm{NK}_{1}$ receptor antagonist) were performed into the caudal nucleus tractus solitarii, the predominant site of termination of cough-related afferents. Lisinopril, but not losartan increased the cough number. This effect was reverted by HOE-140 or CP-99,994. Cough potentiation was also induced by bradykinin. The results support for the first time a central protussive action of lisinopril mediated by an accumulation of bradykinin and substance $\mathrm{P}$.
\end{abstract}

(c) 2015 Elsevier B.V. All rights reserved.

\section{Introduction}

Cough is a very important airway protective reflex, but also characterizes a debilitating disease under chronic conditions. Dry cough is largely considered one of the major side effects of angiotensinconverting enzyme (ACE) inhibitors (Berkin and Ball, 1988), a class of drugs widely used for hypertension, heart failure and postinfarction treatment (Paul et al., 2006). Angiotensin II is the main effector of the renin-angiotensin system (RAS) that controls cardiovascular hemodynamic and blood fluid homeostasis. In mammals there are two primary angiotensin II receptor subtypes, $\mathrm{AT}_{1}$ and $\mathrm{AT}_{2}$ (Paul et al., 2006; Wright and Harding, 2011). Losartan and other sartans block $\mathrm{AT}_{1}$ receptors (McIntyre et al., 1997). They have been associated with low cough incidence in humans, so that they are usually employed to substitute ACE inhibitors in patients displaying as side effect persistent cough (e.g., Paster et al., 1998; Mutolo et al., 2013 also for further Refs.). The mechanism of ACE inhibitorinduced cough remains unclear, but likely involves mainly the protussive mediators bradykinin and substance $P$, agents that are degraded by ACE and therefore accumulated in the respiratory system when the enzyme is inhibited (e.g., Bali et al., 2014; Fox et al.,

\footnotetext{
* Corresponding author.

E-mail address: donatella.mutolo@unifi.it (D. Mutolo).
}

1996; Moreaux et al., 2001; Tomaki et al., 1996; Mutolo et al., 2010, 2013 also for further Refs.).

In a previous study (Mutolo et al., 2013), we have shown that cough upregulation induced by intravenous administration of losartan is lower than that induced by lisinopril both in awake and anesthetized rabbits. Since losartan and lisinopril cross the blood-brain barrier (Pediconi et al., 2005; Ranadive et al., 1992; Tan et al., 2005), a central action of these drugs on the cough reflex can be hypothesized especially at the level of the caudal nucleus tractus solitarii (NTS), the main central terminus of cough-related afferents (Kubin and Davies, 1995; Kubin et al., 2006; Mutolo et al., 2007).

Apart from their role in cardiovascular regulation, RAS components within the central nervous system have other functions mediated by $\mathrm{AT}_{1}$ and/or $\mathrm{AT}_{2}$ receptors (Paul et al., 2006; Premer et al., 2013; Wright and Harding, 2011). In particular, previous studies have demonstrated that several neuromodulators, including angiotensin II acting on $\mathrm{AT}_{1}$ receptors, are involved in cardiovascular regulation within the NTS (Arnold et al., 2010; Cheng et al., 2010, 2012; Kasparov et al., 1998; Mosqueda-Garcia et al., 1990). Accordingly, high levels of ACE (Rogerson et al., 1995) and high densities of $\mathrm{AT}_{1}$ receptors have been found at the level of the NTS in the rabbit (Aldred et al., 1993) as well as in many other mammals including humans (Paul et al., 2006; Premer et al., 2013; Wright and Harding, 2011). 
An attempt was made to ascertain a central action of losartan and lisinopril at the level of the caudal NTS and provide evidence supporting the hypothesis that upregulation of the cough reflex in the rabbit treated with lisinopril could be due, at least in part, to the same mechanisms already suggested to be active at the peripheral level. Thus, we carried out the present study on pentobarbital sodium-anesthetized, spontaneously breathing rabbits by evoking the cough reflex in response to both mechanical and chemical stimulation of the tracheobronchial tree. Changes in the cough reflex induced by microinjections of lisinopril, losartan, bradykinin, HOE140 (a bradykinin $\mathrm{B}_{2}$ receptor antagonist) and $\mathrm{CP}-99,994$ (an $\mathrm{NK}_{1}$ receptor antagonist) into the caudal NTS were investigated.

\section{Materials and methods}

\subsection{Ethical approval}

All animal care and experimental procedures were conducted in accordance with the Italian legislation and the official regulations of the European Community Council on the use of laboratory animals (Directive 86/609/EEC and 2010/63/UE). The study was approved by the Animal Care and Use Committee of the University of Florence. All efforts were made to minimize both the number of animals used and their suffering. Experimental procedures and details about the methods employed have previously been described (Cinelli et al., 2013; Mutolo et al., 2007, 2008, 2009, 2010, 2012, 2013, 2014).

\subsection{Animal preparation}

Experiments were performed on 43 male New Zealand white rabbits $(2.8-3.5 \mathrm{~kg})$ anesthetized with pentobarbital sodium $(40 \mathrm{mg} / \mathrm{kg}$ i.v., supplemented by $2-4 \mathrm{mg} / \mathrm{kg}$ every $30 \mathrm{~min}$; Sigma-Aldrich, St. Louis, MO). Atropine $(0.15 \mathrm{mg} / \mathrm{kg}$ i.m.) was administered to reduce mucosal secretion in the airways. The adequacy of anesthesia was continuously assessed during the experiment as in our previous studies. The trachea was cannulated and polyethylene catheters were inserted into a femoral artery and vein for monitoring arterial blood pressure and drug delivery, respectively. The $C_{3}$ or $C_{5}$ phrenic root on one side was prepared for recordings. The animal was placed in a prone position and fixed by a stereotaxic head holder and vertebral clamps. The head was ventroflexed for optimal exposure of the dorsal surface of the medulla by occipital craniotomy. Body temperature was maintained at $38.5-39^{\circ} \mathrm{C}$.

\subsection{Recording procedures}

Bipolar platinum electrodes were used to record efferent phrenic nerve activity from the central stump of one cut and desheathed phrenic root. Wire electrodes were used to record abdominal muscle electromyographic (EMG) activity. Phrenic and abdominal activities were amplified, full-wave rectified, and "integrated" (low-pass RC filter, time constant $100 \mathrm{~ms}$ ). Arterial blood pressure and end-tidal $\mathrm{CO}_{2}$ partial pressure were recorded. Cardiorespiratory variables were acquired and analyzed using a personal computer, equipped with an analog-to-digital interface (Digidata 1440, Molecular Devices, Sunnyvale, CA, USA) and appropriate software (Axoscope, Molecular Devices).

\subsection{Microinjection procedures}

Bilateral microinjections were performed at two different sites along the rostrocaudal extent of the caudal NTS, and particularly into the lateral commissural NTS. The first was at the level of the caudal-most end of the area postrema, $0.6-0.8 \mathrm{~mm}$ lateral to the midline and $0.7-0.8 \mathrm{~mm}$ below the dorsal medullary surface. The second was $0.5 \mathrm{~mm}$ more caudal, $0.4-0.5 \mathrm{~mm}$ lateral to the midline and $0.7-0.8 \mathrm{~mm}$ below the dorsal medullary surface. The stereotaxic coordinates were selected according to the atlas of Meessen and Olszewski (1949).

Microinjections (30-50 nl) of the following drugs were performed: losartan (5 mM; Fluka-Sigma-Aldrich), lisinopril ( $1 \mathrm{mM}$; Sigma-Aldrich), bradykinin (0.05 mM; Tocris Bioscience, Bristol, UK), HOE-140 (0.2 mM; Tocris Bioscience), a potent and selective bradykinin $B_{2}$ receptor antagonist, CP-99,994 (1 mM; gift from Pfizer, Groton, CT, USA), an $\mathrm{NK}_{1}$ receptor antagonist and $\mathrm{D}, \mathrm{L}-$ homocysteic acid (DLH, 20 mM; Sigma-Aldrich), a broad-spectrum excitatory amino acid agonist. Only one of these drugs was tested in each preparation unless otherwise stated. Drug concentrations were in the same range as those previously used in in vivo preparations (Arnold et al., 2010; Caligiorne et al., 1996; Kasparov et al., 1998; Mutolo et al., 2008). In particular, the concentrations of lisinopril and losartan were based on the knowledge that the antihypertensive potency of lisinopril is $\sim 5$ times higher than that of losartan (see e.g., Mutolo et al., 2013). All drugs were dissolved in $0.9 \% \mathrm{NaCl}$ solution. Control injections of equal volumes of the vehicle solution at the responsive sites were also performed. The localization of injection sites is illustrated in Fig. 1. Green fluorescent latex microspheres (LumaFluor, New City, NY, USA) were injected for post hoc confirmation of injection sites within the caudal NTS of some preparations ( 3 for losartan and 4 for lisinopril).

\subsection{Stimulation procedures}

Both mechanical and chemical stimulation of the tracheobronchial tree were employed to induce cough. Mechanical stimulation was delivered by a custom-built device recently described and validated (Mutolo et al., 2014) using a $0.5 \mathrm{~mm}$ diameter nylon fiber with a smoothed tip inserted through a lateral port of the tracheal cannula. The device allowed to set the number of forth and back movements or cycles (1-3 cycles), shaft velocity (10-20 mm/s), and shaft displacement (10-20 mm). Mechanical stimulation was adjusted to the following parameters: 1 cycle, $15 \mathrm{~mm} / \mathrm{s}$ velocity, and $15 \mathrm{~mm}$ displacement. These parameters proved to produce a bout of 2-4 coughs. The stimulation protocol comprised three stimulation trials performed in succession (at $\sim 1$ min interval) before drug administration, repeated $\sim 5$ min after the completion of all the microinjections and at appropriate intervals (at least $5 \mathrm{~min}$ ) until complete recovery was observed.

Chemical stimulation of the tracheobronchial tree was performed by means of citric acid inhalation (for details see Mutolo et al., 2009). Citric acid (1 M, Sigma-Aldrich) was freshly dissolved in $0.9 \% \mathrm{NaCl}$ solution and nebulized. The opening of the tracheal cannula, through which the rabbits were spontaneously breathing, was exposed to a steady stream of the nebulized citric acid solution for $\sim 3 \mathrm{~s}$. This short period as well as time intervals between chemical challenges $>10$ min proved to be adequate to avoid tachyphylaxis. Chemical stimulation was always applied 2-3 min after mechanically-induced cough and caused a bout of several coughs usually immediately followed by a tachypneic response. As a rule, chemical stimulation was performed both before and $\sim 15 \mathrm{~min}$ after the completion of the injections and repeated at appropriate intervals to follow the time course of the recovery process. All stimulation procedures were performed at least 5-6 min after each supplemental dose of pentobarbital to avoid its possible immediate influence on the recorded variables.

\subsection{Histology}

The histological control of pipette tracks and injection sites was performed as previously described (for details, see Mutolo et al., 2007, 2012). Medullary sections in which injection sites 
B

A
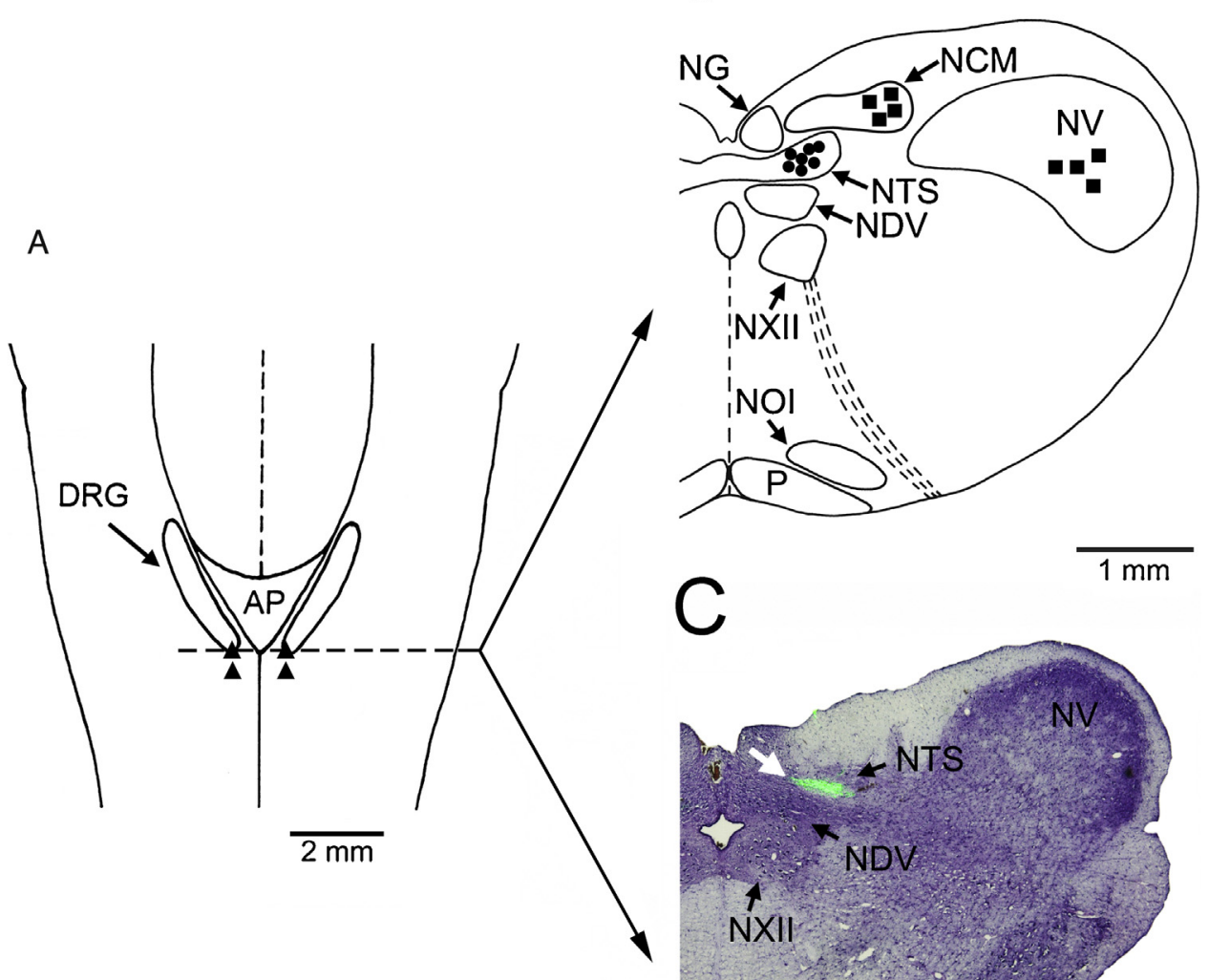

$1 \mathrm{~mm}$

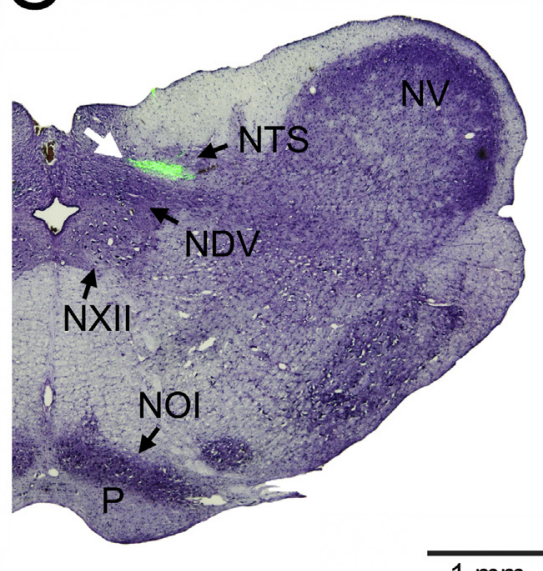

$1 \mathrm{~mm}$

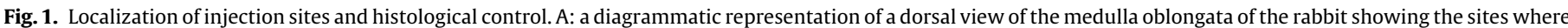

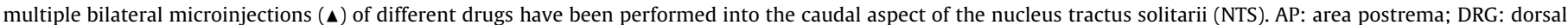

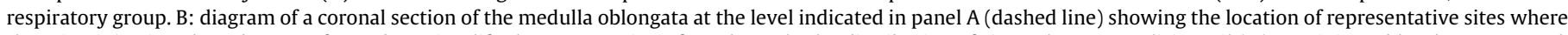

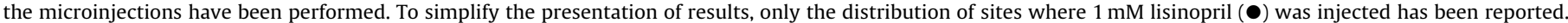

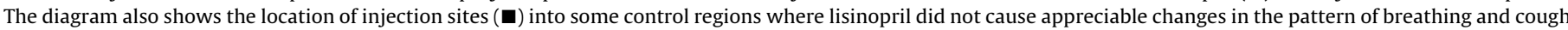

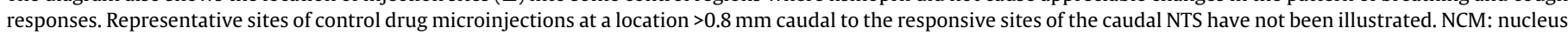

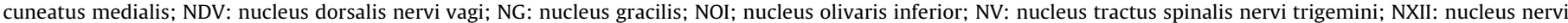

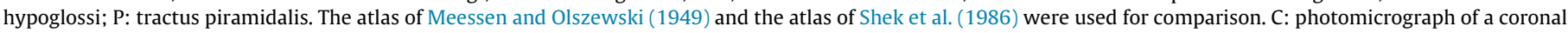

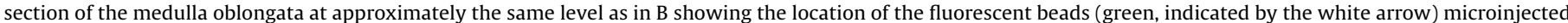

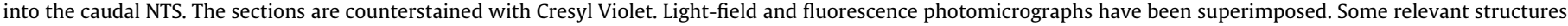
have been indicated. (For interpretation of the references to color in this figure legend, the reader is referred to the web version of this article.)

were marked by fluorescent microspheres were examined in a light and/or epifluorescence microscopy (Eclipse E400, Nikon, Japan) equipped with the Nikon Intensilight C-HGFI mercury-fiber illuminator. Photomicrographs were taken with a Nikon DS-Fi1 digital camera. Illustrations were prepared in Adobe Photoshop CS3 (Adobe Systems Incorporated, San Jose, CA, USA). The atlas of Meessen and Olszewski (1949) as well as the more recent atlas of Shek et al. (1986) were used for comparison.

\subsection{Data collection and analysis}

Respiratory variables were measured during eupneic breathing and reflex responses. The inspiratory $\left(T_{\mathrm{I}}\right)$ and expiratory $\left(T_{\mathrm{E}}\right)$ times, as well as the total duration of the respiratory cycle $\left(T_{\mathrm{T}}\right)$ were measured on recordings of raw phrenic nerve activity (Mutolo et al., 2014; Poliacek et al., 2011). The respiratory frequency was subsequently calculated (breaths/min). Peak amplitude (arbitrary units) of the phrenic nerve activity and abdominal EMG activity were measured on integrated traces and normalized by expressing them as a fraction (or percentage) of the highest achievable amplitude observed in each animal, i.e., in relative units (RU). Breathing pattern variables were measured for an average of five consecutive breaths prior to and following drug microinjections. Furthermore, systolic and diastolic blood pressures were measured at $2 \mathrm{~s}$ intervals and mean arterial pressure was calculated as the diastolic pressure plus one-third of the pulse pressure. The measurement periods of cardiorespiratory variables were the same selected for cough-related variables (see below). Owing to the small variations in respiratory and cardiovascular variables within each measurement period, average values were taken as single measurements for the purpose of analysis. Similarly, cardiorespiratory variables were also measured before and after DLH microinjections at the time when the maximum response occurred.

The cough motor pattern in response to mechanical or chemical stimulation of the tracheobronchial tree is characterized by repeated coughs. Respiratory variables of coughs (cough-related variables) included the cough-related $T_{\mathrm{T}}, T_{\mathrm{I}}$ and $T_{\mathrm{E}}$, peak phrenic amplitude (RU), peak abdominal activity (RU) and the cough 


\section{Mechanical stimulation}

Control
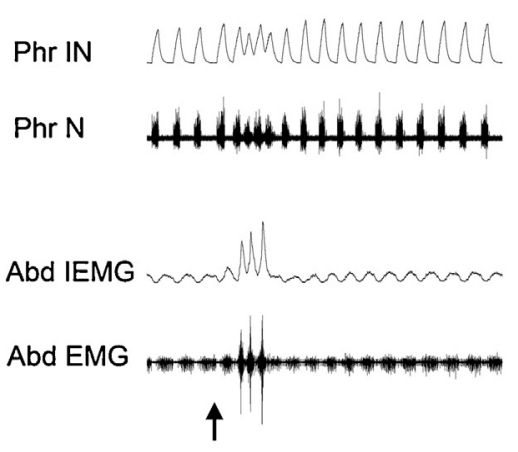

Control

Phr IN

Phr N

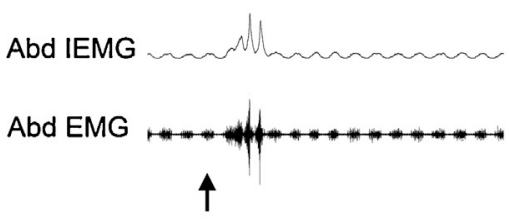

$5 \mathrm{mM}$ Losartan
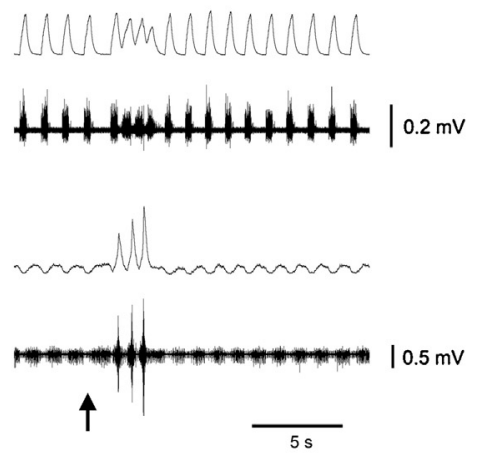

$1 \mathrm{mM}$ Lisinopril

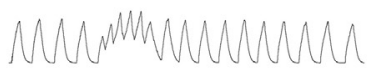

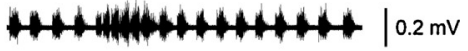

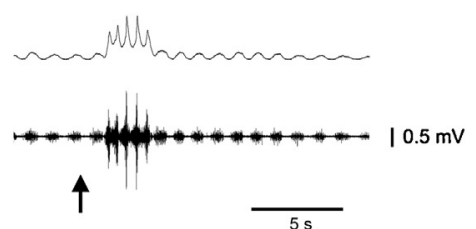

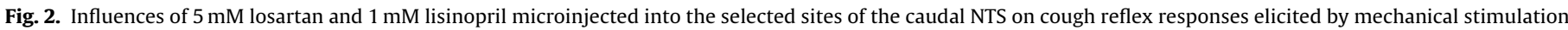

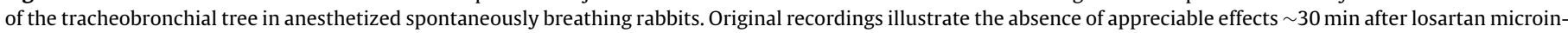

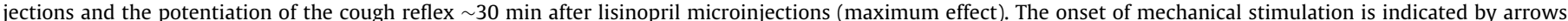

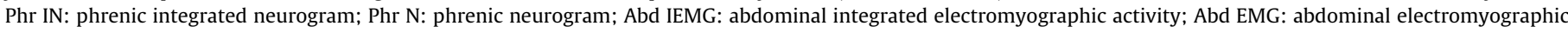
activity.

number, i.e., the number of coughs following each stimulation. Cough-related variables were measured and averaged before and after drug administration at the time when the maximum response occurred as well as at the time when a complete recovery was observed (three trials for mechanical stimulation and a single trial for citric acid inhalation). The average values of cough-related variables were taken as single measurements for subsequent statistical analysis (GraphPad Prism 5, La Jolla, CA, USA). On some occasions, an expiration reflex could occur as the first motor event in a cough epoch (Korpáš and Tomori, 1979; Widdicombe and Fontana, 2006 for further details see Tatar et al., 2008; Mutolo et al., 2007, 2008, 2009, 2012; Cinelli et al., 2013). Expiration reflexes were not considered for data analysis.

Comparisons were performed by means of the one-way repeated-measures ANOVA followed by Student-Newman-Keuls tests. The same statistical analysis was employed to evaluate the reversion of the lisinopril-induced effects by the bradykinin $B_{2}$ receptor antagonist $\mathrm{HOE}-140$ and the $\mathrm{NK}_{1}$ receptor antagonist $\mathrm{CP}$ 99,994 . DLH-induced changes in cardiorespiratory variables as well as the bradykinin effects on the cough reflex in the presence of $\mathrm{CP}$ 99,994 were evaluated by the Student's paired $t$-test. All reported values are means \pm SE; $p<0.05$ was taken as significant.

\section{Results}

Bilateral microinjections $(n=7)$ of $5 \mathrm{mM}$ losartan $(30-50 \mathrm{nl}$; $150-250 \mathrm{pmol}$ ) into the caudal NTS did not produce any effect on the cough response to both mechanical and chemical stimulation of the tracheobronchial tree (Figs. 2 and 3; Table 1). In contrast, bilateral microinjections $(n=7)$ of $1 \mathrm{mM}$ lisinopril (30-50 $\mathrm{nl} ; 30-50 \mathrm{pmol}$ ) increased the number of coughs induced by mechanical and chemical stimulations of the tracheobronchial tree (Figs. 2 and 3; Table 1). These effects were already apparent on mechanically-induced cough within $\sim 5$ min and were fully developed for both types of stimulation at $\sim 30$ min after the completion of the microinjections. Cough-related variables resumed control values within $60 \mathrm{~min}$.

Since lisinopril-induced cough potentiation could be linked to an accumulation of bradykinin (Bali et al., 2014; Fox et al., 1996; Moreaux et al., 2001), bilateral microinjections $(n=7)$ of $0.05 \mathrm{mM}$ bradykinin ( $30-0 \mathrm{nl}$; $1.5-2.5 \mathrm{pmol}$ ) were performed into the caudal NTS. About 10 min after the microinjections (maximum effect), the cough number increased from $3.13 \pm 0.40$ to $4.33 \pm 0.35(p<0.001)$ during mechanical stimulation and from $3.71 \pm 0.42$ to $5.86 \pm 0.45$ $(p<0.001)$ during chemical stimulation (see also Fig. 4). No changes in the other cough-related variables were observed (not shown). The recovery occurred within $\sim 60 \mathrm{~min}$. Accordingly, microinjections of $0.2 \mathrm{mM} \mathrm{HOE}-140(30-50 \mathrm{nl} ; 6-10 \mathrm{pmol})$ into the same caudal NTS sites performed $\sim 30$ min after lisinopril $(n=5)$ reverted within $\sim 10$ min lisinopril-induced potentiation of the cough reflex (Fig. 5A).

To verify whether substance $P$ accumulation is also involved in the lisinopril-induced potentiation of the cough reflex (Bali 


\section{Citric acid inhalation}

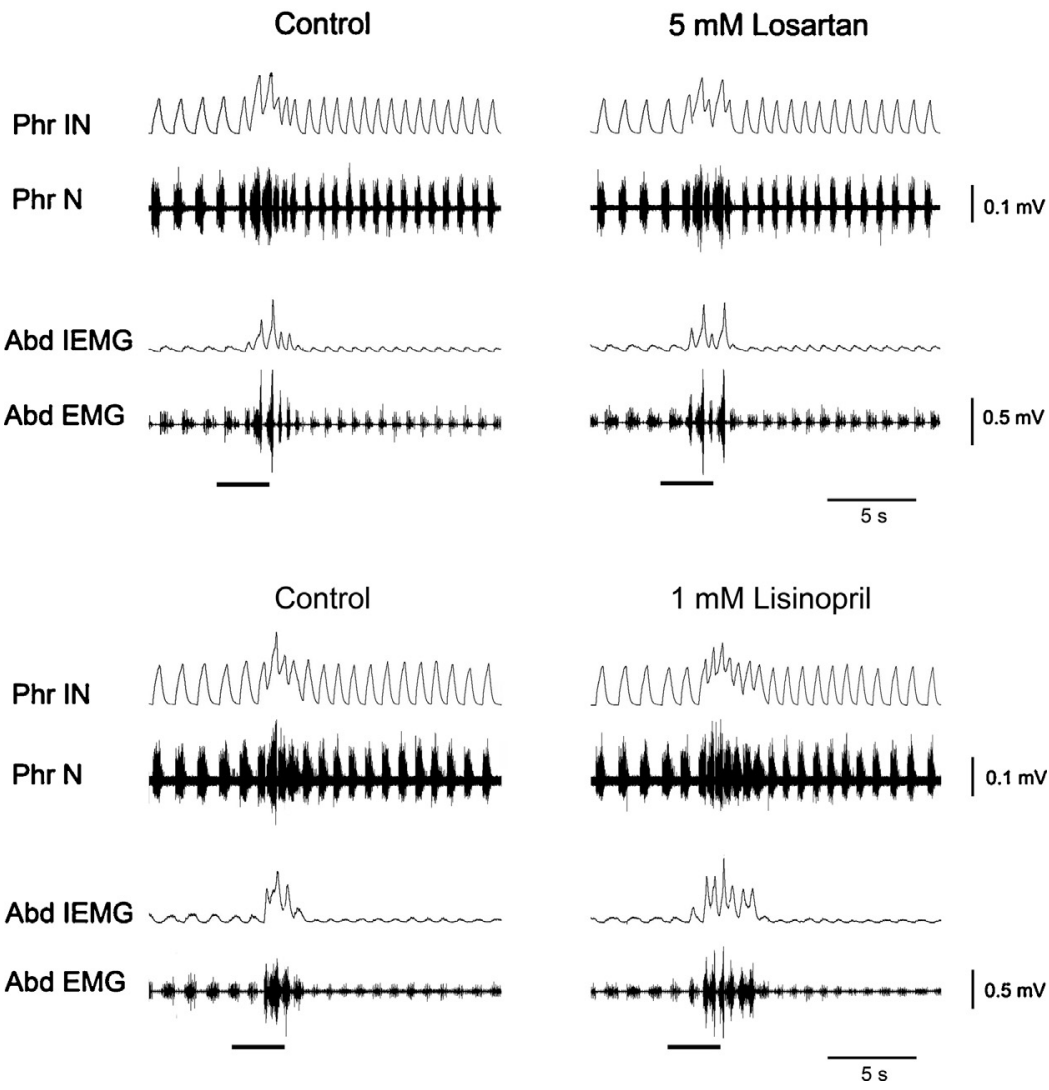

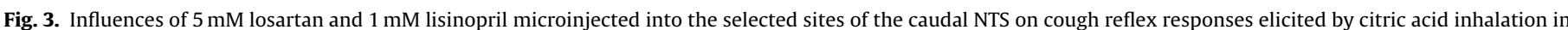

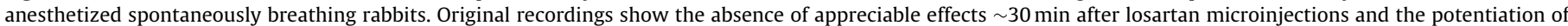

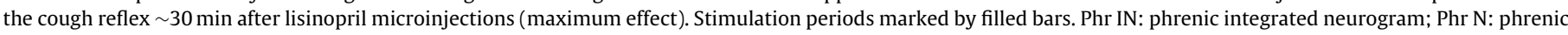
neurogram; Abd IEMG: abdominal integrated electromyographic activity; Abd EMG: abdominal electromyographic activity.

et al., 2014; Moreaux et al., 2001; Tomaki et al., 1996), we tried to revert lisinopril-induced effects by microinjections of CP-99,994, an $\mathrm{NK}_{1}$ receptor antagonist. It has already been shown that substance P microinjected into the caudal NTS markedly potentiates cough reflex responses (Mazzone et al., 2005; Mutolo et al., 2007) while $10 \mathrm{mM} \mathrm{CP-99,994} \mathrm{microinjected} \mathrm{into} \mathrm{the} \mathrm{same} \mathrm{site} \mathrm{abolishes}$ them (Mutolo et al., 2008). Thus, we searched for a concentration of the $\mathrm{NK}_{1}$ receptor antagonist that injected into the caudal NTS did not cause any antitussive effect under control conditions, but could abolish lisinopril-induced potentiation. A concentration of $1 \mathrm{mM}$ was selected in preliminary trials $(n=4)$. Microinjections of
$1 \mathrm{mM} \mathrm{CP}-99,994(30-50 \mathrm{nl} ; 30-50 \mathrm{pmol} ; n=5)$ into the same caudal NTS sites executed $\sim 30 \mathrm{~min}$ after lisinopril blocked within $\sim 10 \mathrm{~min}$ lisinopril-induced potentiation of the cough reflex (Fig. 5B).

The results show that both the $B_{2}$ receptor antagonist and the $\mathrm{NK}_{1}$ receptor antagonist are able to completely abolish coughpotentiating effects (the facilitatory effects on the cough reflex responses) induced by lisinopril. Since bradykinin is known to facilitate the release of substance $P$ from rat sensory neurons in culture as well as from peripheral terminals of capsaicine-sensitive primary afferents (for a review, see Couture et al., 2001), an attempt was made to ascertain whether bradykinin could be responsible

Table 1

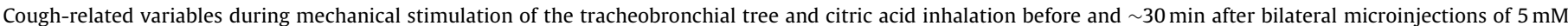
losartan ( $n=7)$ and $1 \mathrm{mM}$ lisinopril $(n=7)$ into the caudal NTS.

\begin{tabular}{|c|c|c|c|c|c|c|}
\hline & $\mathrm{CN}$ & $T_{\mathrm{T}}(\mathrm{s})$ & $T_{\mathrm{I}}(\mathrm{s})$ & $T_{\mathrm{E}}(\mathrm{s})$ & PPA (RU) & PAA (RU) \\
\hline \multicolumn{7}{|c|}{ Mechanical stimulation } \\
\hline Control & $3.16 \pm 0.22$ & $0.53 \pm 0.04$ & $0.36 \pm 0.03$ & $0.17 \pm 0.01$ & $0.63 \pm 0.03$ & $0.58 \pm 0.03$ \\
\hline 5 mM Losartan & $3.07 \pm 0.27$ & $0.55 \pm 0.03$ & $0.37 \pm 0.02$ & $0.18 \pm 0.01$ & $0.61 \pm 0.03$ & $0.58 \pm 0.02$ \\
\hline Control & $2.81 \pm 0.19$ & $0.55 \pm 0.03$ & $0.37 \pm 0.02$ & $0.18 \pm 0.01$ & $0.62 \pm 0.02$ & $0.57 \pm 0.04$ \\
\hline $1 \mathrm{mM}$ Lisinopril & $4.38 \pm 0.35^{*}$ & $0.56 \pm 0.02$ & $0.38 \pm 0.02$ & $0.17 \pm 0.01$ & $0.66 \pm 0.03$ & $0.57 \pm 0.03$ \\
\hline \multicolumn{7}{|c|}{ Citric acid inhalation } \\
\hline Control & $3.86 \pm 0.51$ & $0.51 \pm 0.01$ & $0.35 \pm 0.02$ & $0.17 \pm 0.01$ & $0.62 \pm 0.03$ & $0.49 \pm 0.03$ \\
\hline 5 mM Losartan & $3.79 \pm 0.51$ & $0.54 \pm 0.02$ & $0.35 \pm 0.01$ & $0.19 \pm 0.01$ & $0.60 \pm 0.05$ & $0.48 \pm 0.03$ \\
\hline Control & $3.43 \pm 0.48$ & $0.55 \pm 0.02$ & $0.37 \pm 0.02$ & $0.18 \pm 0.01$ & $0.61 \pm 0.03$ & $0.50 \pm 0.03$ \\
\hline $1 \mathrm{mM}$ Lisinopril & $5.71 \pm 0.64^{*}$ & $0.56 \pm 0.03$ & $0.38 \pm 0.03$ & $0.17 \pm 0.02$ & $0.62 \pm 0.05$ & $0.49 \pm 0.02$ \\
\hline
\end{tabular}

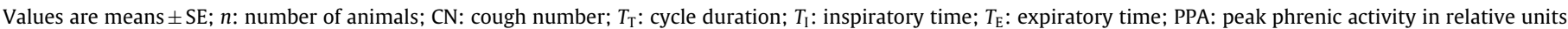
(RU); PAA: peak abdominal activity in relative units (RU).

${ }^{*} p<0.001$ compared with control. 


\section{Mechanical stimulation}

Control
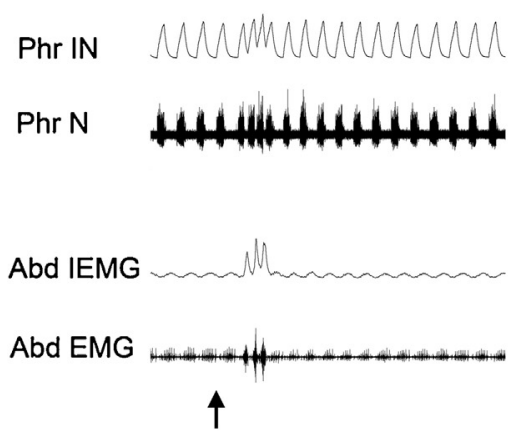

$0.05 \mathrm{mM}$ Bradykinin

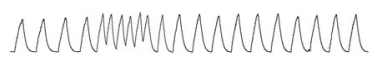

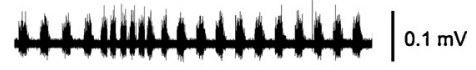

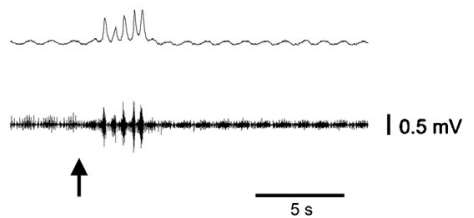

Citric acid inhalation

Control

Phr IN

Phr N
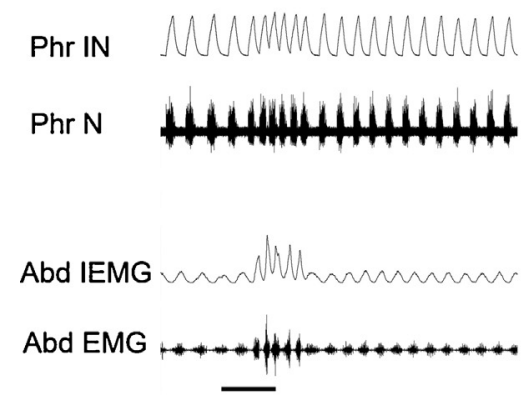

0.05 mM Bradykinin
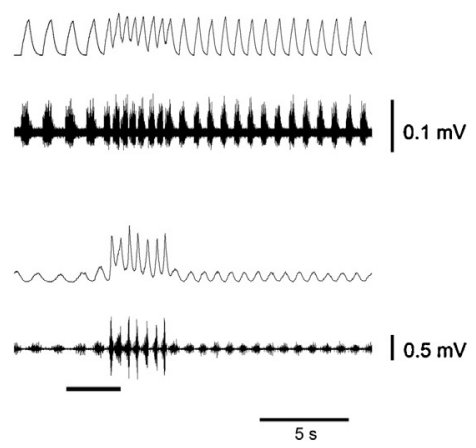

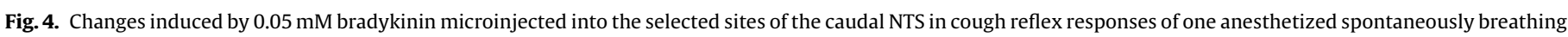

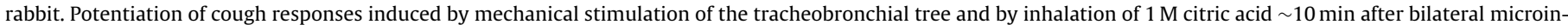

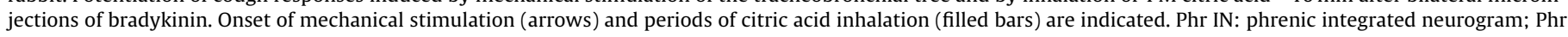
$\mathrm{N}$ : phrenic neurogram; Abd IEMG: abdominal integrated electromyographic activity; Abd EMG: abdominal electromyographic activity.

of the release of substance $P$ at the level of NTS. Thus, in four experiments bilateral microinjections of $0.05 \mathrm{mM}$ bradykinin (30-50 nl; $1.5-2.5 \mathrm{pmol}$ ) were performed $\sim 5 \mathrm{~min}$ after bilateral microinjections of $1 \mathrm{mMCP}-99,994(30-50 \mathrm{nl}$; 30-50 pmol) into the same caudal NTS sites. About $10 \mathrm{~min}$ after bradykinin microinjections, the cough reflex was not potentiated: the cough number remained fairly constant during mechanical stimulation (from $3.05 \pm 0.27$ to $2.85 \pm 0.17 ; p>0.05$ ) and during chemical stimulation (from $4.10 \pm 0.31$ to $3.87 \pm 0.37 ; p>0.05$ ).

Although the main focus of our study was on cough responses, we also observed that bilateral microinjections of losartan, lisinopril or bradykinin into the caudal NTS did not affect respiratory variables during eupneic control breathing (see e.g., control recordings before reflex responses in Figs. 2-4; statistical data not shown). Similarly, no consistent changes in arterial blood pressure were observed (mean arterial pressure was always between 96 and $105 \mathrm{mmHg}$ ). A general evaluation of cardiorespiratory variables under control conditions has been provided in previous reports (Mutolo et al., 2007, 2008, 2009). The correspondence of lisinopril injection sites to the NTS regions involved in cardiovascular regulation, where glutamate microinjections cause decreases in arterial blood pressure (e.g., Cheng et al., 2012; Mosqueda-Garcia et al., 1990), was also investigated. Bilateral microinjections of $20 \mathrm{mM}$ DLH (30-50 nl; 600-1000 pmol), per- formed in four preparations before lisinopril administration, consistently decreased within 3-4 min mean arterial blood pressure $(-22.25 \pm 1.49 \mathrm{mmHg} ; p<0.05)$. These injections also caused increases in the respiratory rate (from $51.2 \pm 3.1$ to $72.4 \pm 4.1$ breaths/min; $p<0.005$ ) mainly due to decreases in $\mathrm{T}_{\mathrm{E}}$ (from $0.83 \pm 0.05$ to $0.53 \pm 0.05 \mathrm{~s} ; p<0.005$ ) associated with the suppression of the abdominal muscle activity. No attempts were made to elicit cough reflex responses during DLH-induced effects.

In four additional preparations, bilateral control microinjections of $1 \mathrm{mM}$ lisinopril were performed at different medullary locations sufficiently far from the responsive sites (Cinelli et al., 2013; Lipski et al., 1988; Mutolo et al., 2007, 2008, 2009, 2012, 2014; Nicholson, 1985; Sykova and Nicholson, 2008). Four microinjections of $1 \mathrm{mM}$ lisinopril were executed into each of the following neural structures (for comparison, see Meessen and Olszewski, 1949; Shek et al., 1986): the nucleus cuneatus medialis, the nucleus tractus spinalis nervi trigemini and the region located $>0.8 \mathrm{~mm}$ caudal to the responsive NTS sites. In all instances, no appreciable changes in the pattern of breathing and cough responses were observed. In accordance with the results of our previous studies on the NTS region (Mutolo et al., 2007, 2008, 2012, 2014), control injections of equal volumes of the vehicle solution at the responsive sites ( 5 trials 
A

\section{Mechanical stimulation}
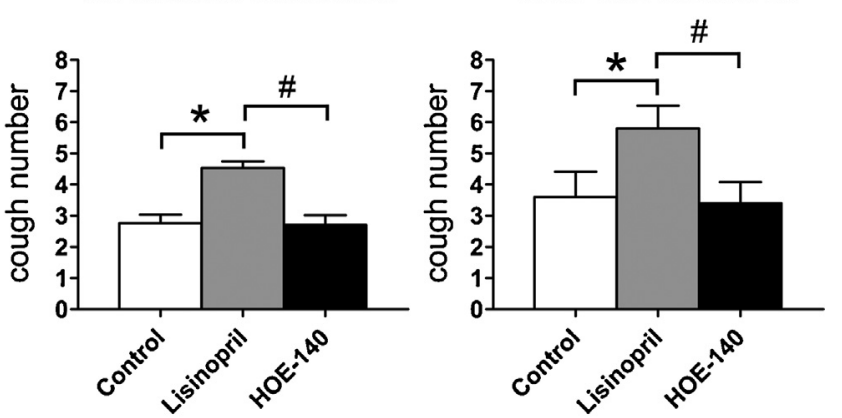

B
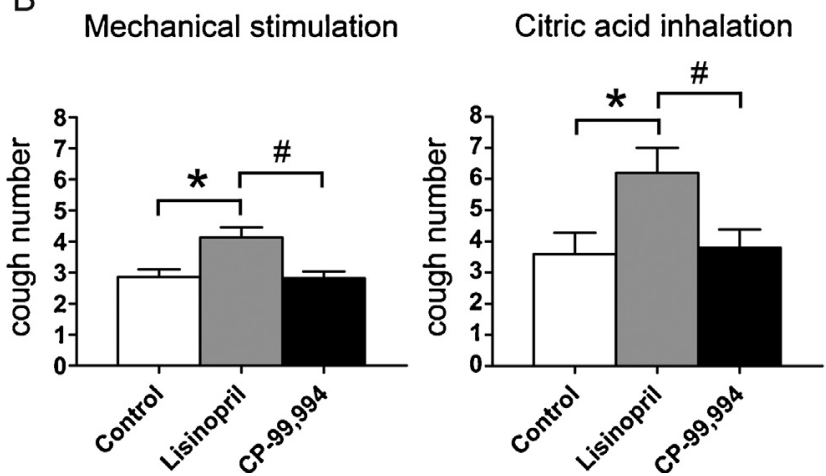

Fig. 5. Blockade of the lisinopril-induced effects by the bradykinin B2 receptor antagonist HOE-140 and the NK1 receptor antagonist CP-99,994 microinjected into the caudal NTS. A: histograms showing the number of coughs induced by mechanical and chemical stimulations under control conditions, $\sim 25 \mathrm{~min}$ after $1 \mathrm{mM}$ lisinopril, and $\sim 10 \mathrm{~min}$ after $0.2 \mathrm{mM} \mathrm{HOE}-140(n=5)$. B: histograms showing the number of coughs induced by mechanical and chemical stimulations under control conditions, $\sim 25 \mathrm{~min}$ after $1 \mathrm{mM}$ lisinopril microinjections, and $\sim 10 \mathrm{~min}$ after $1 \mathrm{mM}$ CP-99,994 $(n=5)$. Each antagonist was microinjected $\sim 30 \mathrm{~min}$ after lisinopril, i.e., during the maximum cough-potentiating effect. Values are means \pm SE. ${ }^{*} p<0.001$ compared with control; $\# p<0.001$ compared with lisinopril. The cough number after HOE-140 or CP-99,994 was not significantly different from control.

performed in 5 different preparations before drug administration) were ineffective.

The localization of the injection sites was confirmed by the histological control (for details see also Mutolo et al., 2007, 2012). An example of the location of fluorescent beads microinjected into the caudal NTS is shown in Fig. 1. The same figure illustrates the localization of injection sites on a dorsal view of the medulla oblongata as well as the distribution of injection sites within the caudal NTS and some control regions. Only the distribution of sites where $1 \mathrm{mM}$ lisinopril was injected has been reported.

\section{Discussion}

This study is the first to provide evidence that, in contrast to losartan, the ACE inhibitor lisinopril microinjected into the caudal NTS induces a potentiation of the cough reflex evoked by both mechanical and chemical stimulation of the tracheobronchial tree. In our opinion, the main novelty of the present results is that they support the notion of a central action of lisinopril that interferes with the catabolism of bradykinin and substance $P$ at the level of the caudal NTS, i.e., at the level of a neural structure with a very important, or even crucial, role in the medullary regulation of this reflex (e.g., Bolser et al., 2006; Bonham et al., 2004; Canning and Mori, 2010, 2011; Mazzone et al., 2005; Mutolo et al., 2007, 2008, 2009, 2012). In other words, the RAS can be suggested to be involved in the central control of the cough reflex. While substance $P$ is well known to upregulate the cough reflex at the level of the NTS (Mazzone et al., 2005; Mutolo et al., 2007), it seems worth mentioning that for the first time it has been shown that also bradykinin within the caudal NTS enhances cough reflex responses.

\subsection{Methodological consideration and general remarks}

We have already discussed in details the reliability of microinjections techniques and the characteristic of the spread of the injectate (Cinelli et al., 2013; Mutolo et al., 2007, 2008, 2009, 2012, 2014). Relatively high drug concentrations (mM) have been shown to be as a rule necessary when using microinjection techniques, as fully discussed in a previous report (Bongianni et al., 2002). The specificity of drug-induced effects is supported by the absence of changes in cough-reflex responses induced by bilateral microinjections of the vehicle solution into the caudal NTS or by drug microinjections into regions sufficiently away from the responsive sites. For a more exhaustive appraisal and discussion on the spread of injected drugs see also Lipski et al., 1988; Nicholson, 1985; Sykova and Nicholson, 2008. Interestingly, changes in mean arterial blood pressure that may affect the cough reflex (Poliacek et al., 2011) were not observed. The absence of consistent changes in mean arterial blood pressure following microinjections of losartan and lisinopril is in agreement with previous studies on the effects of different types of ACE inhibitors or sartans microinjected into the NTS of normotensive control animals (Arnold et al., 2010; Chitravanshi and Sapru, 2011; Katsunuma et al., 2003; Wang et al., 2007). The localization of responsive injection sites was confirmed by the histological control. It appears to correspond fairly well to that of NTS sites of action of agents affecting the cardiovascular system (e.g., Arnold et al., 2010; Cheng et al., 2012; MosquedaGarcia et al., 1990; Tseng et al., 1996). This correspondence was also confirmed by DLH-induced depressor responses.

\subsection{Drug-induced changes in the cough reflex}

The results support our hypothesis that lisinopril could potentiate the cough reflex at the central level through an accumulation of protussive mediators such as bradykinin and substance P. All components necessary for the formation and metabolism of bradykinin and related kinins have been described in the brain, including the NTS (Bhoola et al., 1992; Diz, 1985). In more detail, highaffinity binding sites for bradykinin were found in the NTS (Fior and Fuxe, 1995; Privitera et al., 1992). The biological effects of bradykinin are mediated by its interactions with two distinct bradykinin receptor subtypes, the bradykinin $B_{1}$ and $B_{2}$ receptors. The bradykinin $B_{1}$ receptor is expressed at very low levels and has a limited distribution under normal conditions, but can be induced and upregulated under certain pathological conditions (see e.g., Albert-Weissenberger et al., 2013). Of note, the bradykinin $B_{2}$ receptors have been found to be expressed in the NTS (Murone et al., 1997; Privitera et al., 1992). This was the reason why we used the $B_{2}$ receptor antagonist HOE-140 to corroborate bradykinin involvement in lisinopril-induced effects. The absence of bradykinin-induced pressor effects is consistent with similar results obtained with lisinopril microinjections into the caudal NTS that actually may induce bradykinin accumulation. On the contrary, decreases in mean arterial blood pressure have been previously obtained by microinjections of similar doses of bradykinin into the medial NTS of the rat. However, the site of these microinjections appears to be fairly different, located more rostrally at the level of the area postrema (Caligiorne et al., 1996).

The peptide substance $P$ displays a widespread distribution in both the central and peripheral nervous system. After binding to the $\mathrm{NK}_{1}$ receptors, substance $\mathrm{P}$ regulates many functions in the central nervous system (for a review, see Munoz and Covenas, 
2014). In particular, at the level of the NTS an important role of substance $P$ in the central plasticity induced by vagal afferent fibers as well as in cough potentiation has been suggested (Bonham et al., 2004). Accordingly, substance P microinjections into the caudal NTS potentiate the cough reflex induced by both mechanical and chemical stimulation of the tracheobronchial tree (Mazzone et al., 2005; Mutolo et al., 2007), an effect that was counteracted by intracerebroventricular administration of $\mathrm{NK}_{1}$ receptor antagonists (Mazzone et al., 2005). The antitussive role of $\mathrm{NK}_{1}$ receptor antagonism was confirmed by the observation that microinjections of $10 \mathrm{mM}$ CP-99,994 into the caudal NTS abolished the cough reflex induced by mechanical stimulation of the tracheobronchial tree (Mutolo et al., 2008). In the present study, relatively low concentrations of the same $\mathrm{NK}_{1}$ receptor antagonist did not affect the cough reflex under control conditions, but counteracted lisinoprilinduced effects, thus supporting an involvement of substance P in their mediation. In addition, the results strongly suggest that the complete blockade of lisinopril-induced cough potentiation either by the bradykinin $\mathrm{B}_{2}$ receptor antagonist or by the $\mathrm{NK}_{1}$ receptor antagonist could be due to a bradykinin-induced release of substance P probably from NTS sensory neurons or from the terminals of primary afferent fibers.

The potential sources of bradykinin to the NTS may involve several sites in the central nervous system. Immunoreactive bradykinin-like activity was detected in the hypothalamus, pituitary gland, cerebellum, cortex and, interestingly, also in the medulla oblongata (for a review, see Bhoola et al., 1992 also for further Refs.). Substance P may originate from different sources, such as bronchopulmonary C-fiber afferents, esophageal vagal afferents, trigeminal afferents, NTS interneurons, and higher brain centers such as medullary raphé nuclei (for Refs. and discussion on the possible role of substance P see Mutolo et al., 2008). The presynaptic or postsynaptic site of action of bradykinin or substance P in determining cough potentiation is a matter of speculation. However, a probable presynaptic action of bradykinin on sensory C-fibers leading to substance P release (Bhoola et al., 1992; Couture et al., 2001) as well as a postsynaptic action of substance P on NTS neurons of the cough afferent pathway (Bonham et al., 2004 also for further Refs.) can be suggested. In agreement with this view, our experiments show that the bradykinin-induced potentiation of cough reflex responses was completely abolished by the presence of the $\mathrm{NK}_{1}$ receptor antagonist within the NTS.

Losartan microinjections did not affect cough reflex responses, consistently with previous results obtained by i.v. administration (Mutolo et al., 2013). This outcome strengthens our interpretation since its involvement in the blockade of $\mathrm{AT}_{1}$ receptors cannot lead per se to an accumulation of bradykinin and substance P. In addition, the activation of $\mathrm{AT}_{2}$ receptors by angiotensin II may inhibit ERK1/2 activity (Fischer et al., 1998), an effect that has been proved to downregulate the cough reflex at the level of the caudal NTS (Mutolo et al., 2012). Further, the activation of $\mathrm{AT}_{2}$ receptors has been suggested to have a role in the release of endogenous opioids (Bali et al., 2014) that are well-known to exert not only analgesic, but also antitussive effects (see e.g. Mutolo et al., 2008). In agreement with our interpretation, evidence has been provided that $\mathrm{AT}_{2}$ receptors are present in the NTS, including its caudal portion (Lenkei et al., 1997; Luoh and Chan, 1998; Wang et al., 2012). Nevertheless, present results do not allow us to rule out completely that losartan microinjected into different medullary areas may have some effects on cough reflex responses.

Consistently with our previous findings on ACE inhibitors (Mutolo et al., 2010, 2013), the cough number was the only variable affected by lisinopril and bradykinin. The interpretation of this finding is obscure, but it can be related to the existence of a central gating mechanism that does not participate in the control of the breathing pattern, but specifically regulates the cough num- ber (Bolser et al., 2006). By contrast, in previous studies by our group not only the cough number, but also the intensity of other cough-related variables were modified by antitussive drugs (Cinelli et al., 2013; Mutolo et al., 2007, 2008, 2009, 2012, 2014). However, the reasons of this discrepancy are at present only speculative.

In conclusion, the results support our contention that lisinopril, but not losartan causes a potentiation of the cough reflex just at the level of the caudal NTS, the main central terminus of cough-related afferents, thus implying a role of the RAS in the central regulation of cough. The protussive effects of ACE inhibitors may be related to an action on NTS sensory neurons due to a bradykinin-induced release of substance P. Since both pro- and antinociceptive roles of the RAS have also been described (Bali et al., 2014), we suggest that studies on the involvement of the RAS in pain and cough modulation could lead to novel therapeutic approaches especially for chronic pathological conditions.

\section{Acknowledgements}

This study was supported by grants from the Ministry of Education, University and Research. E. Cinelli is supported by a postdoctoral fellowship from the Fondazione Internazionale Menarini.

\section{References}

Albert-Weissenberger, C., Siren, A.L., Kleinschnitz, C., 2013. Ischemic stroke and traumatic brain injury: the role of the kallikrein-kinin system. Prog. Neurobiol. 101-102, 65-82.

Aldred, G.P., Chai, S.Y., Song, K., Zhuo, J., MacGregor, D.P., Mendelsohn, F.A., 1993. Distribution of angiotensin II receptor subtypes in the rabbit brain. Regul. Pept. 44, 119-130.

Arnold, A.C., Isa, K., Shaltout, H.A., Nautiyal, M., Ferrario, C.M., Chappell, M.C., Diz D.I., 2010. Angiotensin-(1-12) requires angiotensin converting enzyme and AT1 receptors for cardiovascular actions within the solitary tract nucleus. Am. J. Physiol. Heart Circ. Physiol. 299, H763-H771.

Bali, A., Singh, N., Jaggi, A.S., 2014. Renin-angiotensin system in pain: existing in a double life. J. Renin Angiotensin Aldosterone Syst. 15, 329-340.

Berkin, K.E., Ball, S.G., 1988. Cough and angiotensin converting enzyme inhibition. Br. Med. J. (Clin. Res. Ed) 296, 1279

Bhoola, K.D., Figueroa, C.D., Worthy, K., 1992. Bioregulation of kinins: kallikreins kininogens, and kininases. Pharmacol. Rev. 44, 1-80.

Bolser, D.C., Poliacek, I., Jakus, J., Fuller, D.D., Davenport, P.W., 2006. Neurogenesis of cough, other airway defensive behaviors and breathing: a holarchical system. Respir. Physiol. Neurobiol. 152, 255-265.

Bongianni, F., Mutolo, D., Carfi, M., Pantaleo, T., 2002. Respiratory responses to ionotropic glutamate receptor antagonists in the ventral respiratory group of the rabbit. Pflugers Arch. 444, 602-609.

Bonham, A.C., Sekizawa, S.I., Joad, J.P., 2004. Plasticity of central mechanisms for cough. Pulm. Pharmacol. Ther. 17, 453-457.

Caligiorne, S.M., Santos, R.A., Campagnole-Santos, M.J., 1996. Cardiovascular effects produced by bradykinin microinjection into the nucleus tractus solitarii of anesthetized rats. Brain Res. 720, 183-190.

Canning, B.J., Mori, N., 2010. An essential component to brainstem cough gating identified in anesthetized guinea pigs. FASEB J. 24, 3916-3926.

Canning, B.J., Mori, N., 2011. Encoding of the cough reflex in anesthetized guinea pigs. Am. J. Physiol. Regul. Integr. Comp. Physiol. 300, R369-R377.

Cheng, W.H., Lu, P.J., Ho, W.Y., Tung, C.S., Cheng, P.W., Hsiao, M., Tseng, C.J., 2010 Angiotensin II inhibits neuronal nitric oxide synthase activation through the ERK1/2-RSK signaling pathway to modulate central control of blood pressure. Circ. Res. 106, 788-795.

Cheng, W.H., Lu, P.J., Hsiao, M., Hsiao, C.H., Ho, W.Y., Cheng, P.W., Lin, C.T., Hong, L.Z., Tseng, C.J., 2012. Renin activates PI3K-Akt-eNOS signalling through the angiotensin AT(1) and Mas receptors to modulate central blood pressure control in the nucleus tractus solitarii. Br. J. Pharmacol. 166, 2024-2035.

Chitravanshi, V.C., Sapru, H.N., 2011. Cardiovascular responses elicited by a new endogenous angiotensin in the nucleus tractus solitarius of the rat. Am. J. Physiol. Heart Circ. Physiol. 300, H230-H240.

Cinelli, E., Bongianni, F., Pantaleo, T., Mutolo, D., 2013. Suppression of the cough reflex by alpha 2 -adrenergic receptor agonists in the rabbit. Physiol. Rep. 1, e00122.

Couture, R., Harrisson, M., Vianna, R.M., Cloutier, F., 2001. Kinin receptors in pain and inflammation. Eur. J. Pharmacol. 429, 161-176.

Diz, D.I., 1985. Bradykinin and related peptides in central control of the cardiovascular system. Peptides 6 (Suppl. 2), 57-64.

Fior, D.R., Fuxe, K., 1995. Bradykinin modulation of alpha 2-adrenoceptors in the nucleus tractus solitarii of the rat. An in vitro autoradiographical study. Neuropharmacology 34, 81-88. 
Fischer, T.A., Singh, K., O'Hara, D.S., Kaye, D.M., Kelly, R.A., 1998. Role of AT1 and AT2 receptors in regulation of MAPKs and MKP-1 by ANG II in adult cardiac myocytes. Am. J. Physiol. Heart Circ. Physiol. 275, H906-H916.

Fox, A.J., Lalloo, U.G., Belvisi, M.G., Bernareggi, M., Chung, K.F., Barnes, P.J., 1996. Bradykinin-evoked sensitization of airway sensory nerves: a mechanism for ACE-inhibitor cough. Nat. Med. 2, 814-817.

Kasparov, S., Butcher, J.W., Paton, J.F., 1998. Angiotensin II receptors within the nucleus of the solitary tract mediate the developmental attenuation of the baroreceptor vagal reflex in pre-weaned rats. J. Auton. Nerv. Syst. 74, 160-168

Katsunuma, N., Tsukamoto, K., Ito, S., Kanmatsuse, K., 2003. Enhanced angiotensin-mediated responses in the nucleus tractus solitarii of spontaneously hypertensive rats. Brain Res. Bull. 60, 209-214.

Korpáš, J., Tomori, Z., 1979. Cough and Other Respiratory Reflexes. Karger, Basel Switzerland

Kubin, L., Alheid, G.F., Zuperku, E.J., McCrimmon, D.R., 2006. Central pathways of pulmonary and lower airway vagal afferents. J. Appl. Physiol. 101, 618-627.

Kubin, L., Davies, R.O., 1995. Central pathways of pulmonary and airway vagal afferents. In: Hornbein, T.F. (Ed.), Regulation of breathing, vol. 79. 79. Dekker, New York, pp. 219-284.

Lenkei, Z., Palkovits, M., Corvol, P., Llorens-Cortes, C., 1997. Expression of angiotensin type-1 (AT1) and type-2 (AT2) receptor mRNAs in the adult rat brain: a functional neuroanatomical review. Front. Neuroendocrinol. 18 , 383-439.

Lipski, J., Bellingham, M.C., West, M.J., Pilowsky, P., 1988. Limitations of the technique of pressure microinjection of excitatory amino acids for evoking responses from localized regions of the CNS. J. Neurosci. Methods 26, 169-179.

Luoh, H.F., Chan, S.H., 1998. Participation of AT1 and AT2 receptor subtypes in the tonic inhibitory modulation of baroreceptor reflex response by endogenous angiotensins at the nucleus tractus solitarii in the rat. Brain Res. 782, 73-82.

Mazzone, S.B., Mori, N., Canning, B.J., 2005. Synergistic interactions between airway afferent nerve subtypes regulating the cough reflex in guinea-pigs. J. Physiol. 569, 559-573.

McIntyre, M., Caffe, S.E., Michalak, R.A., Reid, J.L., 1997. Losartan, an orally active angiotensin (AT1) receptor antagonist: a review of its efficacy and safety in essential hypertension. Pharmacol. Ther. 74, 181-194.

Meessen, H., Olszewski, J.A., 1994. A Cytoarchitectonic Atlas of the Rhomboencephalon of the Rabbit. Karger, Basel.

Moreaux, B., Advenier, C., Gustin, P., 2001. Role of bradykinin and tachykinins in the potentiation by enalapril of coughing induced by citric acid in pigs. Fundam. Clin. Pharmacol. 15, 23-29.

Mosqueda-Garcia, R., Tseng, C.J., Appalsamy, M., Robertson, D., 1990. Cardiovascular effects of microinjection of angiotensin II in the brainstem of renal hypertensive rats. J. Pharmacol. Exp. Ther. 255, 374-381.

Munoz, M., Covenas, R., 2014. Involvement of substance P and the NK-1 receptor in human pathology. Amino Acids 46, 1727-1750.

Murone, C., Paxinos, G., McKinley, M.J., Oldfield, B.J., Muller-Esterl, W., Mendelsohn, F.A., Chai, S.Y., 1997. Distribution of bradykinin B2 receptors in sheep brain and spinal cord visualized by in vitro autoradiography. J. Comp. Neurol. 381, 203-218.

Mutolo, D., Bongianni, F., Cinelli, E., Fontana, G.A., Pantaleo, T., 2008. Modulation of the cough reflex by antitussive agents within the caudal aspect of the nucleus tractus solitarii in the rabbit. Am. J. Physiol. Regul. Integr. Comp. Physiol. 295, R243-R251.

Mutolo, D., Bongianni, F., Cinelli, E., Giovannini, M.G., Pantaleo, T., 2012. Suppression of the cough reflex by inhibition of ERK1/2 activation in the caudal nucleus tractus solitarii of the rabbit. Am. J. Physiol. Regul. Integr. Comp. Physiol. 302, R976-R983.

Mutolo, D., Bongianni, F., Cinelli, E., Pantaleo, T., 2009. Role of excitatory amino acids in the mediation of tracheobronchial cough induced by citric acid inhalation in the rabbit. Brain Res. Bull. 80, 22-29.

Mutolo, D., Bongianni, F., Evangelista, S., Cinelli, E., Pantaleo, T., 2010. Effects of zofenopril and ramipril on cough reflex responses in anesthetized and awake rabbits. J. Cardiovasc. Pharmacol. Ther. 15, 384-392.

Mutolo, D., Bongianni, F., Fontana, G.A., Pantaleo, T., 2007. The role of excitatory amino acids and substance $P$ in the mediation of the cough reflex within the nucleus tractus solitarii of the rabbit. Brain Res. Bull. 74, 284-293.
Mutolo, D., Cinelli, E., Bongianni, F., Evangelista, S., Pantaleo, T., 2013. Comparison between the effects of lisinopril and losartan on the cougn reflex in anesthetized and awake rabbits. J. Physiol. Pharmacol. 64, 201-210.

Mutolo, D., Cinelli, E., Bongianni, F., Pantaleo, T., 2014. Inhibitory control of the cough reflex by galanin receptors in the caudal nucleus tractus solitarii of the rabbit. Am. J. Physiol. Regul. Integr. Comp. Physiol. 307, R1358-R1367.

Nicholson, C., 1985. Diffusion from an injected volume of a substance in brain tissue with arbitrary volume fraction and tortuosity. Brain Res. 333, 325-329.

Paster, R.Z., Snavely, D.B., Sweet, A.R., Draper, R.A., Goldberg, A.I., Soffer, B.A., Sweet, C.S., 1998. Use of losartan in the treatment of hypertensive patients with a history of cough induced by angiotensin-converting enzyme inhibitors. Clin. Ther. 20, 978-989.

Paul, M., Poyan, M.A., Kreutz, R., 2006. Physiology of local renin-angiotensin systems. Physiol. Rev. 86, 747-803.

Pediconi, D., Martarelli, D., Fontanazza, A., Pompei, P., 2005. Effects of losartan and irbesartan administration on brain angiotensinogen mRNA levels. Eur. J. Pharmacol. 528, 79-87.

Poliacek, I., Morris, K.F., Lindsey, B.G., Segers, L.S., Rose, M.J., Corrie, L.W., Wang, C., Pitts, T.E., Davenport, P.W., Bolser, D.C., 2011. Blood pressure changes alter tracheobronchial cough: computational model of the respiratory-cough network and in vivo experiments in anesthetized cats. J. Appl. Physiol. 111, 861-873.

Premer, C., Lamondin, C., Mitzey, A., Speth, R.C., Brownfield, M.S., 2013. Immunohistochemical localization of AT1a, AT1b, and AT2 angiotensin Il receptor subtypes in the rat adrenal, pituitary, and brain with a perspective commentary. Int. J. Hypertens 175, 428.

Privitera, P.J., Daum, P.R., Hill, D.R., Hiley, C.R., 1992. Autoradiographic visualization and characteristics of [125I] bradykinin binding sites in guinea pig brain. Brain Res. 577, 73-79.

Ranadive, S.A., Chen, A.X., Serajuddin, A.T., 1992. Relative lipophilicities and structural-pharmacological considerations of various angiotensin-converting enzyme (ACE) inhibitors. Pharm. Res. 9, 1480-1486.

Rogerson, F.M., Schlawe, I., Paxinos, G., Chai, S.Y., McKinley, M.J., Mendelsohn, F.A., 1995. Localization of angiotensin converting enzyme by in vitro autoradiography in the rabbit brain. J. Chem. Neuroanat. 8, 227-243.

Shek, J.W., Wen, G.Y., Wisniewski, H.M., 1986. Atlas of the Rabbit Brain and Spinal Cord. Karger.

Sykova, E., Nicholson, C., 2008. Diffusion in brain extracellular space. Physiol. Rev. 88, 1277-1340.

Tan, J., Wang, J.M., Leenen, F.H., 2005. Inhibition of brain angiotensin-converting enzyme by peripheral administration of trandolapril versus lisinopril in Wistar rats. Am. J. Hypertens. 18, 158-164.

Tatar, M., Hanacek, J., Widdicombe, J., 2008. The expiration reflex from the trachea and bronchi. Eur. Respir. J. 31, 385-390.

Tomaki, M., Ichinose, M., Miura, M., Hirayama, Y., Kageyama, N., Yamauchi, H., Shirato, K., 1996. Angiotensin converting enzyme (ACE) inhibitor-induced cough and substance P. Thorax 51, 199-201.

Tseng, C.J., Liu, H.Y., Lin, H.C., Ger, L.P., Tung, C.S., Yen, M.H., 1996. Cardiovascular effects of nitric oxide in the brain stem nuclei of rats. Hypertension 27 36-42.

Wang, G., Coleman, C.G., Glass, M.J., Zhou, P., Yu, Q., Park, L., Anrather, J., Pickel, V.M., Iadecola, C., 2012. Angiotensin II type 2 receptor-coupled nitric oxide production modulates free radical availability and voltage-gated $\mathrm{Ca}^{2+}$ currents in NTS neurons. Am. J. Physiol. Regul. Integr. Comp. Physiol. 302, R1076-R1083.

Wang, W.Z., Gao, L., Pan, Y.X., Zucker, I.H., Wang, W., 2007. AT1 receptors in the nucleus tractus solitarii mediate the interaction between the baroreflex and the cardiac sympathetic afferent reflex in anesthetized rats. Am. J. Physiol. Regul. Integr. Comp. Physiol. 292, R1137-R1145.

Widdicombe, J., Fontana, G., 2006. Cough: what's in a name. Eur. Respir. J. 28, 10-15.

Wright, J.W., Harding, J.W., 2011. Brain renin-angiotensin-a new look at an old system. Prog. Neurobiol. 95, 49-67. 